\title{
Emergence of G8P[6] rotavirus strains in Korean neonates
}

\author{
Su-Kyung Lee ${ }^{1 \dagger}$, Seoheui Choi ${ }^{2 \dagger}$, Seon-Hee Shin², Eun Jin Lee ${ }^{1}$, Jungwon Hyun ${ }^{1}$, Jae-Seok Kim³ \\ and Hyun Soo Kim ${ }^{1 *}$ (D)
}

\begin{abstract}
Background: Rotaviruses are the major causes of pediatric gastroenteritis worldwide. The genotypic distribution of rotavirus strains shows temporal and geographical fluctuations, and knowledge of the molecular epidemiology of rotaviruses is important for the development of vaccines and diagnostic reagents. We investigated VP4 and VP7 capsid genotypes of rotaviruses isolated from 211 stool specimens collected from Korean neonates in a neonatal intensive care unit from September 2017 to March 2018.

Results: Of 211 stool specimens, 15 specimens (7.1\%) were rotavirus-positive. Eleven specimens (73.3\%) were G8P[6] type and 4 (26.7\%) were G4P[6] type. Sequence analysis revealed that all G8 sequences in this study showed the highest nucleotide identity to G8 sequences of G8P [8] rotavirus strains isolated in Vietnam in 2014, and P[6] gene sequences showed the highest nucleotide identity to P[6] sequences of G4P[6] strains detected in Korea in 2012. Only one amino acid difference in VP7 was found in 3 of the 11 G8P[6] strains in this study, but multiple amino acid substitutions in VP7 were detected between these G8P[6] strains and the commonly used vaccine strains.

Conclusions: This study showed that rotavirus G8P[6] strains were firstly detected at high frequency in Korean neonates from September 2017 to March 2018. These new rotavirus G8P[6] strains were estimated to be derived from reassortment events between the G8 of G8P[8] strains in Asian region and the P[6] of G4[6] in Korea. Whether the emergence of this unusual G8P[6] strain reflects continuous prevalence or transient occurrence will require continuous monitoring of rotavirus epidemiology.
\end{abstract}

Keywords: Rotavirus, Genotype, G8P[6], Korean, Neonate

\section{Background}

Rotaviruses are the most common causes of pediatric gastroenteritis worldwide, especially in children younger than 5 years. The virus contains a genome of 11 doublestranded RNA segments surrounded by a triple-layered capsid consisting of a core, inner capsid, and outer capsid layer $[1,2]$. The outer capsid layer is composed of two structural proteins, VP7 (segment 9) and VP4 (segment 4), which are targets of neutralizing antibodies. Based on VP7 and VP4 gene sequences, human group

\footnotetext{
*Correspondence: hskim0901@empas.com

${ }^{\dagger}$ Su-Kyung Lee and Seoheui Choi contributed equally to this work

1 Department of Laboratory Medicine, Hallym University Dongtan Sacred Heart Hospital, Hallym University College of Medicine, 7, Keunjaebong-gil, Hwaseong-si, Gyeonggi-do 18450, South Korea

Full list of author information is available at the end of the article
}

A rotaviruses are classified into $\mathrm{G}$ and $\mathrm{P}$ genotypes, and an epidemiological study has shown that at least $27 \mathrm{G}$ and 37 P genotypes exist [1]. G1-G4 and G9, and P[4], $\mathrm{P}[6]$, and $\mathrm{P}[8]$ are the most frequent $\mathrm{G}$ and $\mathrm{P}$ genotypes, respectively $[1,3]$. The genotypic distribution of rotavirus strains shows temporal and geographical fluctuations [4]; therefore, continuous monitoring of rotavirus molecular epidemiology is important for the development of vaccines, monitoring vaccine effectiveness, and epidemiological study of endemic and epidemic rotavirus infections.

In Korea, G1P[8] is the most frequent genotype in children, and G4P[6] is the most frequent genotype in neonates [3, 5-8]. The predominance of the G4P[6] genotype in Korean neonates has been frequently reported in several studies from 1999 to 2016 [5-9]. Interestingly, 
G4P[6] predominance was not reported in other countries. However, the genotype G8P[6], which has not been reported in Korean neonates, has been recently frequently detected in a neonatal intensive care unit of one hospital. In the current study, we characterized the VP7 and VP4 capsid genotypes of these new G8P[6] strains.

\section{Results}

\section{Genotyping of rotavirus}

The positive rate of rotavirus antigen testing in the NICU in the study period was $7.1 \%(15 / 211)$. Of the 15 rotavirus-positive samples, 11 (73.3\%) were G8P[6] type and 4 (26.7\%) were G4P[6] type (Table 1 ). The day of admission to the NICU when rotavirus was detected was the 1st day for 11 patients, 4th for 1 patient, 7th for 2 patients, and 30th for 1 patient (Table 1). BLAST searches of 11 G8P [6] strains revealed that all G8 sequences in this study showed the highest nucleotide identity to G8 sequences of G8P [8] rotavirus strains isolated in Vietnam in 2014 [10] (GenBank accession number: LC074743.1_G8P[8]) and $\mathrm{P}[6]$ gene sequences in this study showed the highest nucleotide identity to $\mathrm{P}[6]$ sequences of G4P[6] strains detected in Korea in 2012 (KF650090.1_G4P[6], KF650087.1_G4P[6]).

\section{Phylogenetic and similarity analyses of rotavirus G8P[6] strains}

Phylogenetic trees and Simplot analysis showed genetic distances among the rotavirus reference strains (Figs. 1,
2,3). Phylogenetic analysis showed that the G8 sequences in this study were the closest to G8 of G8P[8] strains from Vietnam in 2014 (LC074743.1_G8P[8]), followed by G8 of G8P[8] from Thailand in 2014 (LC169967.1 G8P[8]) and Japan in 2014 (LC103091.1_G8P[8]), G8 of G8P[6] from Malawi [11] (AB749176.1_G8P[6], AB749177.1_G8P[6], AB749178.1_G8P[6], AB749181.1_ G8P[6], AB749182.1_G8P[6], AB749183.1_G8P[6]), and then by G11, G9, G3, G12, G2, G1, and G4 strains from Korea (Fig. 1). Phylogenetic analysis showed that the $\mathrm{P}[6]$ sequences in this study were the closest to $\mathrm{P}[6]$ of G4P[6] strains from Korea (KF650091.1, KF650090.1, KF650087.1, KF650095, KF650086_G4P[6]), followed by P[6] of G2P[6] from Korea (AY150893.1_G2P[6]), $\mathrm{P}[6]$ of G12P[6] from Korea (EF059920.1_G12P[6]), and P[6] of G8P[6] from Malawi [11] (AB749203.1_G8P[6], AB749208.1_G8P[6], AB749207.1_G8P[6], AB749201.1_ G8P[6], AB749206.1_G8P[6], AB749202.1_G8P[6]), and then by P[8] strains from Korea (EU679400.1_G1P[8] and EU679395.1_G1P[8]) (Fig. 2). Simplot analysis of VP7 genes showed that the region of first 650 nucleotides was more variable than the latter part (Fig. 3).

\section{Comparison of the deduced amino acids of VP7 protein of the G8P[6] strains from this study with those of reference strains}

Of the 11 G8P[6] strains included in this study, only one amino acid difference in VP7 was found in three strains (one G114D or two T209Is) (Fig. 4). Additional

Table 1 Genotypes of rotaviruses detected in a NICU from September 2017 to March 2018

\begin{tabular}{|c|c|c|c|c|c|c|}
\hline $\begin{array}{l}\text { Patient no. } \\
\text { (specimen } \\
\text { no.) }\end{array}$ & Age/sex & $\begin{array}{l}\text { Genotype } \\
\text { of rotavirus }\end{array}$ & $\begin{array}{l}\text { Admission day of NICU } \\
\text { when detecting rotavirus }\end{array}$ & Route of NICU admission & Patient's home town & $\begin{array}{l}\text { Origin } \\
\text { of rotavirus } \\
\text { infection }\end{array}$ \\
\hline 1 & 16 days/M & $\mathrm{G} 8 \mathrm{P}[6]^{\#}$ & Day 1 & Transfer from A clinic & Osan & Outside \\
\hline 2 & 12 days/M & $\mathrm{G} 8 \mathrm{P}[6]^{\#}$ & Day 1 & Transfer from B clinic & Suwon & Outside \\
\hline 3 & 30 days/F & $\mathrm{G} 8 \mathrm{P}[6]^{\#}$ & Day 30 & Birth in this hospital & Pyeongtaek & $\mathrm{NICU}$ \\
\hline 4 & 17 days/M & $\mathrm{G} 8 \mathrm{P}[6]^{\#}$ & Day 7 & Transfer from C clinic & Hwaseong & NICU or outside \\
\hline 5 & 14 days/M & $\mathrm{G} 8 \mathrm{P}[6]^{\#}$ & Day 1 & Transfer from D clinic & Hwaseong & Outside \\
\hline 6 & 21 days/M & $\mathrm{G} 8 \mathrm{P}[6]^{\#}$ & Day 1 & Transfer from E clinic & Hwaseong & Outside \\
\hline 7 & 12 days/M & $\mathrm{G} 8 \mathrm{P}[6]^{\#}$ & Day 1 & Transfer from F clinic & Suwon & Outside \\
\hline 8 & 6 days/M & $\mathrm{G} 8 \mathrm{P}[6]^{\#}$ & Day 1 & Transfer from G hospital & Hwasong & Outside \\
\hline 9 & 8 days/M & $\mathrm{G} 8 \mathrm{P}[6]^{\#}$ & Day 1 & Transfer from $\mathrm{H}$ hospital & Hwasong & Outside \\
\hline 10 & 8 days/M & $\mathrm{G} 8 \mathrm{P}[6]^{\#}$ & Day 1 & Transfer from I clinic & Pyeongtaek & Outside \\
\hline 11 & 12 days/F & $\mathrm{G} 8 \mathrm{P}[6]^{\#}$ & Day 1 & Transfer from I clinic & Osan & Outside \\
\hline 12 & 14 days/M & G4P[6] & Day 1 & Transfer from G hospital & Hwaseong & Outside \\
\hline 13 & 19 days/F & G4P[6] & Day 1 & Transfer from G hospital & Hwaseong & Outside \\
\hline 14 & 15 days/F & G4P[6] & Day 7 & Outpatient clinic in this hospital & Hwaseong & NICU or outside \\
\hline 15 & 5 days/M & G4P[6] & Day 4 & Outpatient clinic in this hospital & Sungnam & NICU or outside \\
\hline
\end{tabular}

Positive rate of rotavirus antigen test in this period: $7.1 \%$ (15 out of 211 patients)

NICU neonatal intensive care unit

\# G8P[6] strains detected in this study 


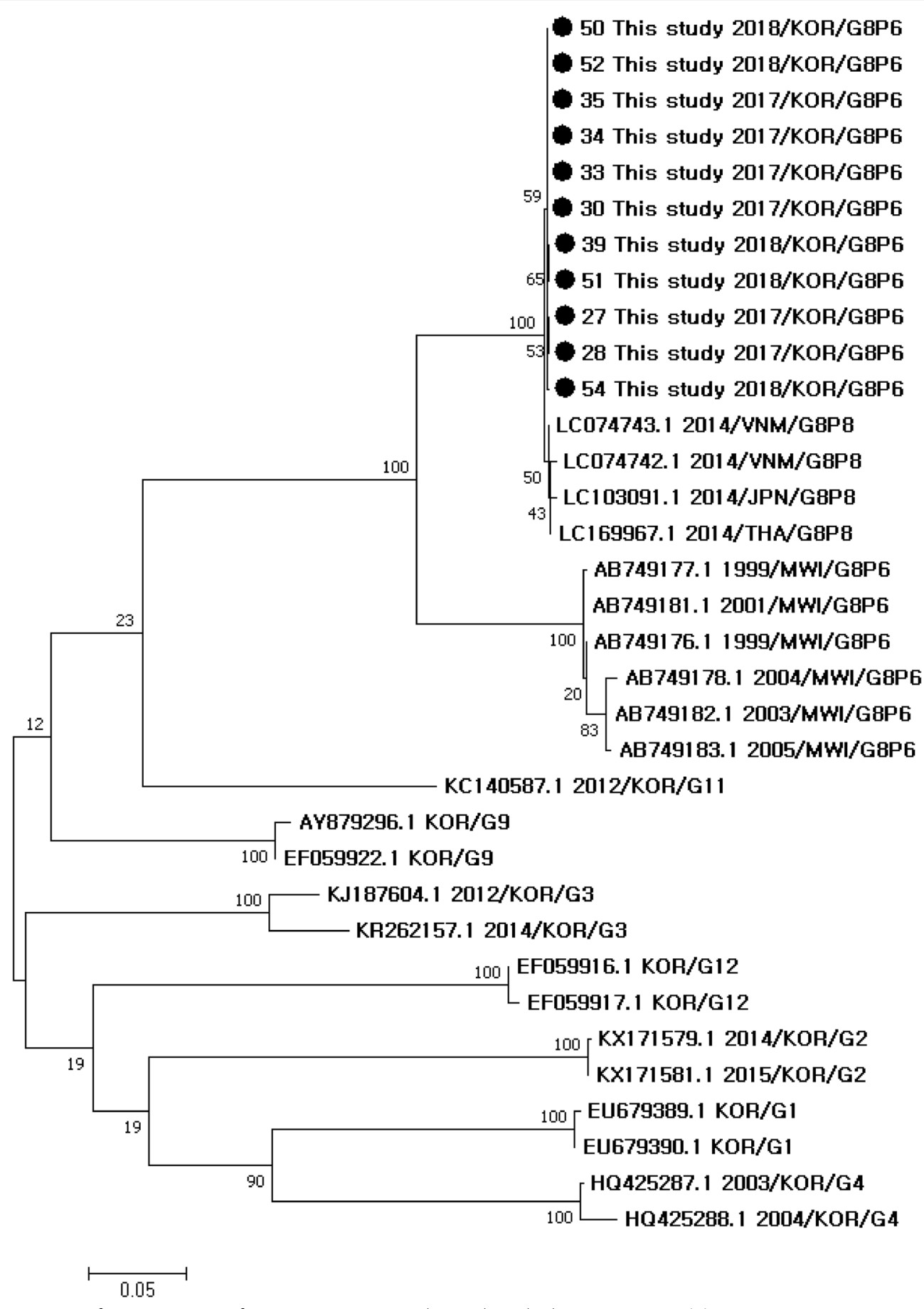

Fig. 1 Phylogenetic tree of VP7 sequences of rotavirus G8 strains in this study and other rotavirus VP7 (G) sequences

one amino acid difference (T113I) was detected when compared with the closest rotavirus strains from GenBank (LC074743.1_G8P[8]). No amino acid differences in epitope 7-1a, 7-1b, and 7-2 regions between the G8 sequences in this study and the closest strains (LC074743.1_G8P[8]) were detected. Multiple amino acid substitutions in VP7 were detected between G8 strains from this study and the commonly used vaccine strains (Fig. 4). 


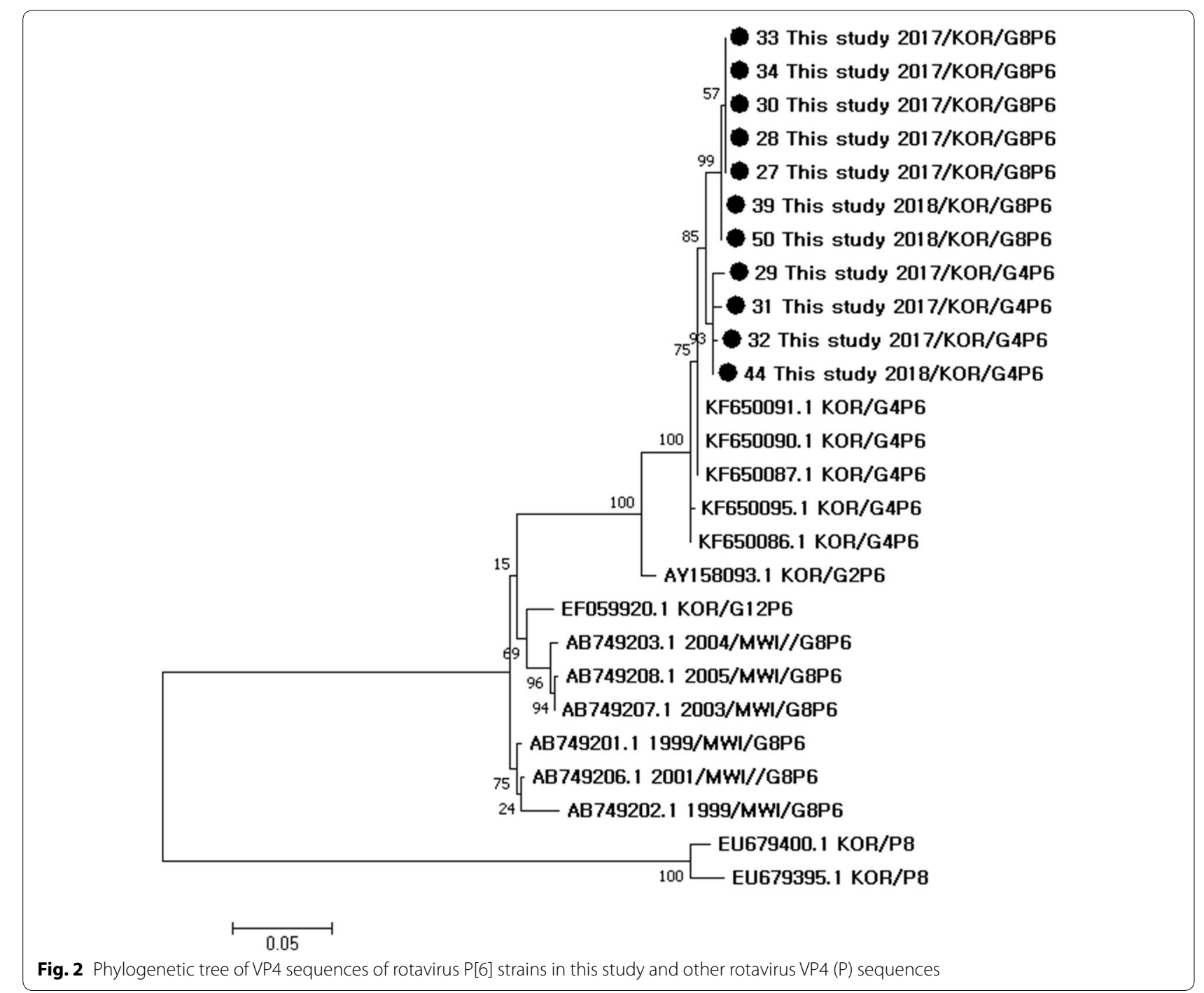

\section{Discussion}

In this study, the rotavirus G8P[6] genotype was detected at unusually high frequency in neonates admitted to the NICU of a university hospital in Korea. This genotype had not been reported previously in Korea. Since several studies have reported that most neonatal rotavirus infections in Korea are caused by G4P [6] strains [5-9], G8P [6] emergence in neonates is remarkable and worth reporting. The G8 genotype was first detected in humans in Indonesia in 1980, and was sporadically detected worldwide, especially in Africa [12-15]. It is often detected in combination with $\mathrm{P}[6]$ in many countries $[12,16]$. To our knowledge, this is the first report of G8P[6] rotavirus infection in Korean neonates.

The sequences of rotaviruses have changed over time. Sequence variations involve nucleotide substitution, recombination, or reassortment [17] of the 11 RNA segments. In this study, the G8 sequences of the G8P[6] strains were the closest to those of G8P [8] found in Vietnam, and the $\mathrm{P}[6]$ sequences of these strains were the closest to those of G4P[6] found in Korea, which suggests reassortment events occurred between the G8 of G8P[8] strain in Asia and the P[6] of G4[6] in Korea. These reassorted or variant strains may be more pathogenic to Korean neonates. Only VP4 and VP7 genes were analyzed in this study. Complete analysis of other gene segments of the rotaviruses will improve our understanding of the overall pattern of nucleotide substitution, recombination, or reassortment [17]. Additionally, we performed genotyping on only NSP5 and VP6 genes of these G8P[6] strains to investigate whether the backbone of these strains is likely to have Wa-like or DS-1-like backbone [10], and the results suggest that these G8P[6] strains appeared to have the 

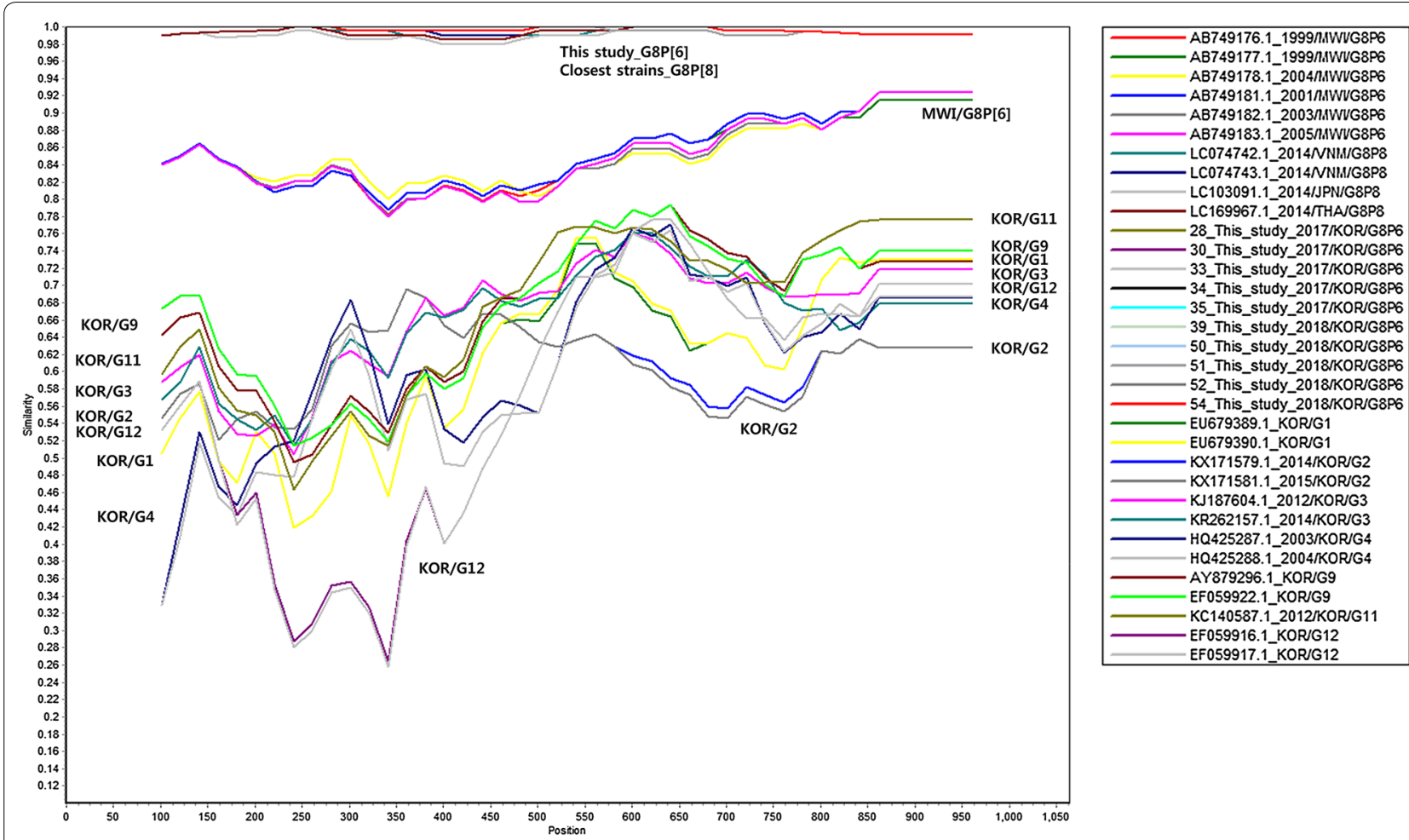

Fig. 3 Similarity analysis of VP7 sequences of rotavirus G8 strains in this study and other rotavirus VP7 (G) sequences

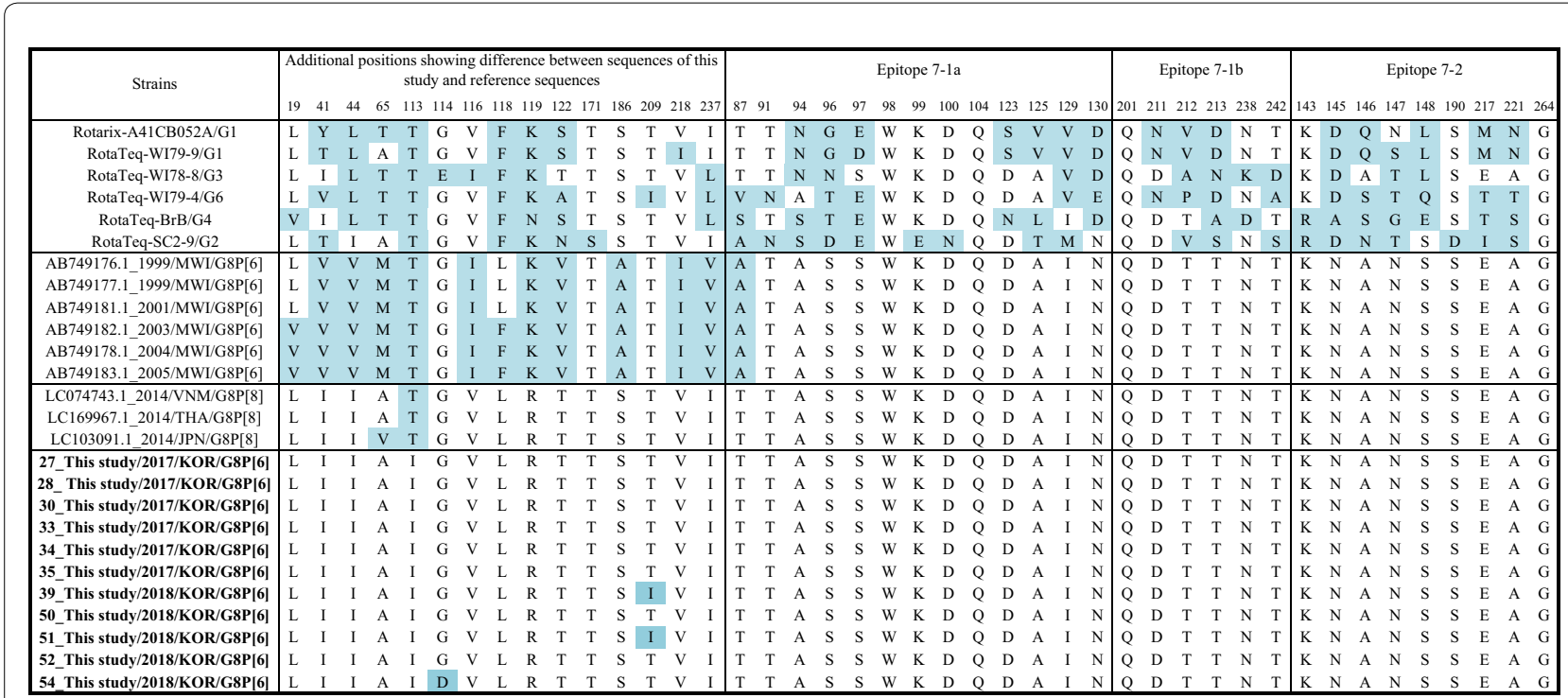

Fig. 4 Deduced amino acid sequences of the antigenic epitopes of the VP7 (G) glycoprotein

possibility of DS-1-like genotype constellation (unpublished data).

Genetic distances between the G8 strains of this study and reference strains in GenBank were estimated through phylogenetic and Simplot analyses. Multiple amino acid substitutions in VP7 were detected between G8 strains from this study and the commonly used vaccine strains. These amino acid substitutions in rotavirus strains may be the cause of escape from host immunity obtained from Rotarix or RotaTeq vaccination. 
In the present study, 9 out of 11 patients who had been infected with rotavirus G8P[6] were diagnosed with rotavirus infection on the 1st day of NICU admission, and these patients were considered to have been infected outside the NICU because rotavirus infection requires an incubation period. On the other hand, the remaining 2 patients were found to be infected on the 7 th and 30th day of NICU admission, and therefore, these infections can be considered to be nosocomial within the NICU. The positive rate of rotavirus antigen testing at the NICU during the study period was $7.1 \%$, which is lower than rotavirus infection rates reported in other studies in Korea [5, 18].

In this study, the G8 sequences of all G8P[6] showed little sequence difference, and all patients with the G8P[6] strain were born in our hospital, or transferred from nearby hospitals or postpartum care centers. Therefore, these 11 G8P[6] strains seemed to have originated from a common ancestor and spread to nearby community areas. Another possibility is that these strains are prevalent in other areas of Korea and were introduced to our hospital around the similar time. Further observation is needed as to whether this new genotype will appear and disappear in the community in short periods or will continue to propagate and disseminate.

\section{Conclusions}

In summary, G8P[6] was frequently isolated from neonates in the NICU of one hospital in a metropolitan area of South Korea from September 2017 to March 2018. These new G8P[6] strains were estimated to be derived from a common ancestor through phylogenetic, similarity, and epitope analyses and these strains were estimated to be derived from reassortment events between the G8 of G8P[8] strains in the Asian region and P[6] of G4[6] in Korea. Whether the emergence of this unusual strain reflects continuous prevalence or transient occurrence will require continuous monitoring of rotavirus epidemiology.

\section{Methods}

\section{Patient samples}

Rotavirus-positive stool samples were collected from Korean neonates in a neonatal intensive care unit. Rotavirus testing was performed on the 1st day of NICU admission regardless of the presence of symptoms and when rotavirus infection was suspected. We investigated VP4 and VP7 capsid genotypes of the rotaviruses from the stool specimens. Between September 2017 and March 2018, 211 fecal specimens were tested for rotavirus antigen (SD BIOLINE Rotavirus assay, Standard Diagnostics, Korea). Of these, 15 rotavirus-positive stool samples (positive rate $7.1 \%$ ) were successively collected in the neonatal intensive care unit (NICU) of Hallym University Dongtan Sacred Heart Hospital. The clinical data collected from the patients' medical records included their age, gender, day of admission at the NICU (i.e., of rotavirus detection). Eleven (73.3\%) were collected from males, and the overall median age of the donors was 14 days (range 5-30 days). This study was approved by the Institutional Review Board of Hallym University Dongtan Sacred Heart Hospital (IRB No. 2017-08-007-001).

\section{Rotavirus $\mathrm{G}$ and $\mathrm{P}$ genotyping}

Rotavirus G (VP7) and P (VP4) genotyping was carried out using RT-PCR and sequencing. Viral RNA was extracted from fecal suspensions by using a QIAamp Viral RNA Mini kit (Qiagen, Hilden, Germany) and the QIAcube platform (Qiagen). The RNA was denatured and reverse-transcribed using the SuperScript ${ }^{\circledR}$ III FirstStrand Synthesis System (Invitrogen, USA). The VP7 and VP4 genes were amplified from the dsRNA genome using specific primer sets, VP7-F/VP7-R and VP4-F/ VP4-R, respectively [1]. Genotyping PCR was conducted using 2.5 U AmpliTaq Gold DNA polymerase Taq (Applied Biosystems, USA). Thermal cycles included initial denaturation at $95{ }^{\circ} \mathrm{C}$ for $15 \mathrm{~min}$ followed by 35 cycles of $95{ }^{\circ} \mathrm{C}$ for $1 \mathrm{~min}, 52{ }^{\circ} \mathrm{C}$ (for VP7) or $50{ }^{\circ} \mathrm{C}$ (for VP4) for $1 \mathrm{~min}$, and $72{ }^{\circ} \mathrm{C}$ for $1 \mathrm{~min}$, and final extension at $72{ }^{\circ} \mathrm{C}$ for $10 \mathrm{~min}$. The PCR products were visualized by electrophoresis in $1 \%$ agarose gel and were analyzed by DNA sequencing using ABI BigDye Terminator v3.1 Cycle Sequencing Kits (Applied Biosystems, USA) and an ABI 3500 XL DNA Analyzer (Applied Biosystems, USA). Genotypes were confirmed using the Basic Local Alignment Search Tool (BLAST) on the National Center for Biotechnology Information (NCBI) website.

\section{Phylogenetic and similarity analyses of rotavirus G8 strains} Phylogenetic and similarity analyses were performed to determine the relationship between most frequently detected rotavirus G8P[6] strains in this study and comparative representative VP7 (G) strains. Reference G sequences were selected from G8 sequences of complete genome assemblies of G8P[6] strains (ASM266995v1_ AB749176.1_G8P[6], ASM266997v1_AB749177.1_ G8P[6], ASM267003v1_AB749178.1_G8P[6], ASM267015v1_AB749181.1_G8P[6], ASM267019v1_ AB749182.1_G8P[6], ASM267029v1_AB749183.1_ G8P[6]), representative Korean strains (EU679389.1_G1, EU679390.1_G1, KX171579.1_G2, KX171581.1_G2, KJ187604.1_G3, KR262157.1_G3, HQ425287.1_G4, HQ425288.1_G4, EF059922.1_G9, AY879296.1_G9, KC140587.1_G11, EF059916.1_G12, EF059917.1_G12), and the closest ones with G8 sequences obtained in this study (LC074743.1_G8P[8], LC103091.1_G8P[8], 
LC169967.1_G8P[8]). Reference P[6] sequences were selected from $P[6]$ sequences of complete genome assemblies of G8P[6] strains from Malawi [11] (AB749203.1_ G8P[6], AB749208.1_G8P[6], AB749207.1_G8P[6], AB749201.1_G8P[6], AB749206.1_G8P[6], AB749202.1_ G8P[6]), representative Korean P[6] strains (KF650091.1, KF650090.1, KF650087.1, KF650095, KF650086_ G4P[6]; AY150893.1_G2P[6]; EF059920.1_G12P[6]), and P[8] strains from Korea (EU679400.1_G1P[8] and EU679395.1_G1P[8]). Representative G8 and P[6] sequences were aligned with MEGA version 7 [19]. Phylogenetic trees were constructed using the maximum likelihood method and Tamura-Nei substitution models with 1000 bootstrap replications. The percentages of similarity between sequences and reference sequences were assessed with the SimPlot program version 3.5.1.

\section{Comparison of the VP7 capsid protein antigenic epitopes of the strains from this study with those of reference strains}

Deduced amino acid sequences of rotavirus VP7 capsid antigens were analyzed and were compared to the representative reference G8 sequences. The rotavirus VP7 protein contains two antigenic epitopes (7-1 and 7-2), which are responsible for evoking neutralizing antibodies, and epitope 7-1 is further subdivided into 7-1a and $7-1 \mathrm{~b}[5,20]$. The capsid hypervariable antigenic epitopes (7-1a, 7-1b, 7-2) of the rotavirus strains obtained in this study were compared to those of reference strains and rotavirus vaccine strains (Rotarix-A41CB052A_G1, RotaTeq-WI79-9_G1, RotaTeq-WI78-8_G3, RotaTeqWI79-4_G6, RotaTeq-BrB_G4, RotaTeq-SC2-9_G2). Multiple sequence alignment and translation to amino acids were conducted using the MEGA version 7 program.

\section{Abbreviations \\ NCBI: National Center for Biotechnology Information; BLAST: Basic Local Alignment Search Tool; NICU: neonatal intensive care unit; RT-PCR: reverse transcription-polymerase chain reaction.}

\section{Authors' contributions}

HSK, SC, and SS designed the experiments; SL and JH performed the experiments and analyzed the data; HSK, SL, SC, SS, EJL, JH, and JK wrote or helped to draft the manuscript. All authors read and approved the final manuscript.

\footnotetext{
Author details

${ }^{1}$ Department of Laboratory Medicine, Hallym University Dongtan Sacred Heart Hospital, Hallym University College of Medicine, 7, Keunjaebong-gil, Hwaseong-si, Gyeonggi-do 18450, South Korea. ${ }^{2}$ Department of Pediatrics, Hallym University Dongtan Sacred Heart Hospital, Hallym University College of Medicine, 7, Keunjaebong-gil, Hwaseong-si, Gyeonggi-do 18450, South Korea. ${ }^{3}$ Department of Laboratory Medicine, Hallym University Kangdong Sacred Heart Hospital, Hallym University College of Medicine, 150, Seongan-ro, Gangdong-gu, Seoul 05355, South Korea.
}

Acknowledgements Not applicable.

\section{Competing interests}

The authors declare that they have no competing interests.

\section{Availability of data and materials}

The datasets used and/or analyzed during the current study are available from the corresponding author on reasonable request.

\section{Consent for publication \\ Not applicable.}

\section{Ethics approval and consent to participate}

This study was approved by the Institutional Review Board of Hallym University Dongtan Sacred Heart Hospital (IRB No. 2017-08-007-001).

\section{Funding}

This work was supported by the National Research Foundation of Korea (NRF2017R1D1A3B03031940) and Hallym University Research Fund.

\section{Publisher's Note}

Springer Nature remains neutral with regard to jurisdictional claims in published maps and institutional affiliations.

Received: 6 April 2018 Accepted: 29 June 2018

Published online: 03 July 2018

\section{References}

1. Desselberger U. Rotaviruses. Virus Res. 2014;190:75-96.

2. WHO. Manual of rotavirus detection and characterization methods. Geneva: World Health Organization; 2009. (http://apps.who.int/iris/handl e/10665/70122). Accessed 15 May 2018.

3. Than VT, Kim W. Prevalence of rotavirus genotypes in South Korea in 1989-2009: implications for a nationwide rotavirus vaccine program. Korean J Pediatr. 2013:56:465-73.

4. Usonis V, Ivaskeviciene I, Desselberger U, Rodrigo C, Pediatric REC. The unpredictable diversity of co-circulating rotavirus types in Europe and the possible impact of universal mass vaccination programmes on rotavirus genotype incidence. Vaccine. 2012;30:4596-605.

5. Kim JS, Kim HS, Hyun J, Kim HS, Song W, Lee KM, et al. Analysis of rotavirus genotypes in Korea during 2013: an increase in the G2P[4] genotype after the introduction of rotavirus vaccines. Vaccine. 2014;32:6396-402.

6. Mun SK, Cho HG, Lee HK, Park SH, Park PH, Yoon MH, et al. High incidence of group A rotaviruses G4P[6] strains among children in Gyeonggi province of South Korea, from 2009 to 2012. Infect Genet Evol. 2016;44:351-5.

7. Kang JO, Kilgore P, Kim JS, Nyambat B, Kim J, Suh HS, et al. Molecular epidemiological profile of rotavirus in South Korea, July 2002 through June 2003: emergence of G4P[6] and G9P[8] strains. J Infect Dis. 2005;192(Suppl 1):S57-63.

8. Kang JO, Kim CR, Kilgore PE, Choi TY. G and P genotyping of human rotavirus isolated in a university hospital in Korea: implications for nosocomial infections. J Korean Med Sci. 2006:21:983-8.

9. Kim JS, Kim SM, Kim HS. High prevalence of rotavirus G4P[6] genotypes among neonates in two Korean hospitals. The Ann Clin Microbiol. 2017;20:63-6

10. Hoa-Tran TN, Nakagomi T, Vu HM, Do LP, Gauchan P, Agbemabiese CA, et al. Abrupt emergence and predominance in Vietnam of rotavirus $A$ strains possessing a bovine-like G8 on a DS-1-like background. Arch Virol. 2016;161:479-82.

11. Nakagomi T, Doan YH, Dove W, Ngwira B, Iturriza-Gomara M, Nakagomi $\mathrm{O}$, et al. G8 rotaviruses with conserved genotype constellations detected in Malawi over 10 years (1997-2007) display frequent gene reassortment among strains co-circulating in humans. J Gen Virol. 2013;94:1273-95.

12. Santos N, Hoshino Y. Global distribution of rotavirus serotypes/genotypes and its implication for the development and implementation of an effective rotavirus vaccine. Rev Med Virol. 2005;15:29-56. 
13. Matsuno S, Hasegawa A, Mukoyama A, Inouye S. A candidate for a new serotype of human rotavirus. J Virol. 1985;54:623-4.

14. Banyai K, Laszlo B, Duque J, Steele AD, Nelson EA, Gentsch JR, et al. Systematic review of regional and temporal trends in global rotavirus strain diversity in the pre rotavirus vaccine era: insights for understanding the impact of rotavirus vaccination programs. Vaccine. 2012;30(Suppl 1):A122-30.

15. Todd S, Page NA, Duncan Steele A, Peenze I, Cunliffe NA. Rotavirus strain types circulating in Africa: review of studies published during 1997-2006. J Infect Dis. 2010;202(Suppl):S34-42.

16. Ahmed S, Klena J, Albana A, Alhamdani F, Oskoff J, Soliman M, et al. Characterization of human rotaviruses circulating in Iraq in 2008: atypical G8 and high prevalence of P[6] strains. Infect Genet Evol. 2013;16:212-7.
17. Doro R, Laszlo B, Martella V, Leshem E, Gentsch J, Parashar U, et al. Review of global rotavirus strain prevalence data from six years post vaccine licensure surveillance: is there evidence of strain selection from vaccine pressure? Infect Genet Evol. 2014;28:446-61.

18. Shim JO, Son DW, Shim SY, Ryoo E, Kim W, Jung YC. Clinical characteristics and genotypes of rotaviruses in a neonatal intensive care unit. Pediatr Neonatol. 2012;53:18-23.

19. Kumar S, Stecher G, Tamura K. MEGA7: molecular evolutionary genetics analysis version 7.0 for bigger datasets. Mol Biol Evol. 2016:33:1870-4.

20. Aoki ST, Settembre EC, Trask SD, Greenberg HB, Harrison SC, Dormitzer PR. Structure of rotavirus outer-layer protein VP7 bound with a neutralizing Fab. Science. 2009;324:1444-7.
Ready to submit your research? Choose BMC and benefit from:

- fast, convenient online submission

- thorough peer review by experienced researchers in your field

- rapid publication on acceptance

- support for research data, including large and complex data types

- gold Open Access which fosters wider collaboration and increased citations

- maximum visibility for your research: over $100 \mathrm{M}$ website views per year

At BMC, research is always in progress.

Learn more biomedcentral.com/submissions 